\title{
Limites e possibilidades para a efetivação da integralidade na atenção à saúde: o Cenário de Ensino em questão
}

\author{
Limits and possibilities for the achievement of integral health care: \\ the Learning Setting in analysis \\ Deborah Varjabedian¹, Camila Sotello Raymundo', Maria Elisabete Guazzelli', Marco Akerman² \\ ${ }^{1}$ Universidade Anhembi Morumbi (UAM) - São Paulo (SP), Brasil. \\ ${ }^{2}$ Faculdade de Medicina do ABC (FMABC) - Santo André (SP), Brasil.
}

DOI: http://dx.doi.org/10.7322/abcshs.v40i3.797

\begin{abstract}
RESUMO
Introdução: A atuação do fisioterapeuta ainda é voltada para o tratamento dos distúrbios cinéticos funcionais em órgãos e sistemas do corpo humano, privilegiando a atenção secundária e terciária à saúde. Deseja-se, no entanto, alcançar no processo de formação, o perfil manifesto no ideário que norteia os princípios da integralidade, que enfatiza a importância da atenção primária. Apesar das mudanças curriculares experimentadas na formação superior em Fisioterapia, organizadas de forma integrada e apoiadas na interdisciplinaridade, percebe-se que o conceito de integralidade não é reproduzido e incorporado de forma efetiva, desde o início da graduação até o momento do estágio prático na clínica/escola da Universidade. Objetivos: Verificar se as propostas presentes na concepção do cenário de ensino foram efetivadas de acordo com as premissas de integralidade de atenção à saúde. Métodos: Na tentativa de buscar respostas para tais questionamentos, foram analisados os documentos diretivos da instituição de ensino Projeto de Desenvolvimento Institucional (PDI), Projeto Pedagógico Institucional (PPI) e o documento Centro Integrado de Saúde (CIS) -, para podermos verificar se tais documentos permitem a proposição de estratégias agregadoras da integralidade na atenção à saúde. Resultados e Conclusão: Tais documentos demonstraram uma sinergia com os princípios humanos fundamentais, para com o ser, para com o aluno e para com a sociedade como um todo, agindo assim, em consonância com os preceitos da integralidade. Não significando, no entanto, que a integralidade fora utilizada como um dos pilares norteadores destes documentos.
\end{abstract}

Palavras-chave: integralidade em saúde; materiais de ensino; fisioterapia.

\begin{abstract}
Introduction: The practice of a physical therapist is still pointing to the treatment of disorders functional kinetic in organs and systems of the human body, focusing the attention secondary and tertiary health care. It is to be hoped, however, to achieve in the formation process the profile manifest ideals that guides the principles of comprehensiveness, which emphasizes the importance of primary care. Despite the curricular changes experienced in higher education in Physiotherapy, organized in an integrated manner and supported on interdisciplinarity, it is clear that the concept of comprehensiveness is not reproduced and incorporated in an effective way, since the beginning of the graduation until the moment of traineeship in clinical/school of the University. Objective: This study examined whether the present proposals on the design of the scenario of education were actioned in accordance with the assumptions of integrality of health care. Methods: In an attempt to find answers to such questions, we analyzed the documents directing the education institution - Project of Institutional Development (PDI), Institutional Pedagogical Project (PPI) and the document Center for Integrated Health (CIS) - , so that we can check if such documents allow the proposition of strategies groups of comprehensiveness in health care. Results and Conclusion: These documents demonstrated a synergy with the principles fundamental human, for the human being, with the student and the society as a whole, acting as well, in line with the precepts of completeness. Does not mean, however, that the entire outside used as one of the pillars of these guiding documents
\end{abstract}

Keywords: integrality in health; teaching materials; physical therapy specialty. 


\section{INTRODUÇÃO}

O modelo pedagógico e profissional adotado na Fisioterapia, a semelhança dos demais cursos da área da saúde, obedeceu por muito tempo a ainda hegemônica óptica especialista e disciplinar, fundamentada em uma perspectiva de diferenciação e compartimentalização clara entre saberes, utilizando-se de modelos de investigação científica pautados pela óptica cartesiana e positivista. A ação do fisioterapeuta foi profundamente atrelada ao modelo pautado pela medicalização da saúde, privilegiando os olhares curativos e reabilitadores e de forma incipiente a atenção preventiva. A doença era, assim, compreendida fundamentalmente como a negação da saúde e vice-versa. De forma reducionista, os modelos de atenção à saúde e de estratégias de formação superior e de pesquisa científica remetiam "saúde", "corpo", "doença”, "motricidade" a uma categorização eminentemente médica.

Muitas foram as dinâmicas que desencadearam o questionamento do modelo médico-assistencialista de atenção à saúde e permitiram refletir sobre novas formas de abordagem em saúde. No cenário nacional, a Reforma Sanitária Brasileira (RFB), que deu origem ao Sistema Único de Saúde (SUS), resultante das tensões entre diferentes elementos como o Estado, a estrutura social, as diferentes ideologias e o próprio setor saúde e suas práxis teve fundamental relevância. Originária fundamentalmente de movimentos sociais da sociedade civil que combatiam o autoritarismo desde os anos 1970, a ideia da Reforma Sanitária surgiu como resposta à crise da saúde surgida durante a ditadura militar e como referente cultural resultante da leitura de experiências em saúde, a exemplo do vivido na Itália. A baixa eficácia da assistência médica, os altos custos do modelo médico-hospitalar, a baixa cobertura dos serviços de saúde em função das necessidades da população, associados à falência do "milagre econômico" da ditadura, a crise do capitalismo mundial no início dos anos 1970 e a queda da legitimidade do autoritarismo fez surgir um espaço de luta para as forças progressistas ${ }^{1}$.

A introdução de um novo ideário que toma esses objetos como complexos, definidos e articulados sob uma nova óptica, determinaram novas lógicas de abordagem. No entanto, o diálogo entre as diferentes formas de saber, expresso nos pressupostos da promoção da saúde e o princípio de integralidade na atenção a saúde reivindicados pelo Sistema Único de Saúde estão longe de serem efetivados.

Sendo assim, a busca pela compreensão das dinâmicas que atuam como facilitadoras ou como impeditivas à efetivação da integralidade na atenção à saúde envolve, não só, a análise da formação superior, do campo da pesquisa e da prática profissional do fisioterapeuta, mas, também, o exame das representações sociais em torno da integralidade na atenção à saúde emanantes dos diferentes atores envolvidos na formação e na ação fisioterapêutica como docentes, discentes, fisioterapeutas inseridos no mercado de trabalho, usuários dos serviços de fisioterapia e outros profissionais de saúde.
É um processo lento, gradativo e complexo, já que envolve mudanças não só da organização dos fazeres como dos saberes, implicando em uma mudança atitudinal frente aos objetos "saúde" e "atenção à saúde".

A incorporação da interdisciplinaridade como nova óptica de organização dos conhecimentos e o desenvolvimento de práticas e ações que busquem a integralidade na atenção à saúde são mudanças profundas e extensas que exigem constante reavaliação, novas análises e a tomada de novas medidas em busca da nova excelência na formação superior.

São poucos os estudos que abordam o papel da clínica-escola no Brasil. Muitos estudos são realizados demonstrando os serviços prestados ou estudos de populações que foram atendidas no serviço. A maioria das publicações são advindas do curso de Psicologia e outras voltadas para hospital escola e hospital veterinário.

A maioria das clínicas-escolas mantém o mesmo mecanismo de funcionamento. Cada área de conhecimento organiza as suas práticas específicas em espaços próprios, desvinculados das redes públicas, do contexto das relações na sociedade e dos modos de vida, em territórios concretos de organização política. Os objetivos acabam sendo os mesmos, ou seja, as clínicas - escolas formam os estagiários e atendem ao públicoque as procura ${ }^{2}$.

Muitas clínicas funcionam como laboratórios de experimentações e de habilidades. Esses modelos de formação contribuem para a manutenção de serviços e clínicas-escola que fortalecem a formação disciplinar como espaço de treinamento de técnicas e procedimentos. Sendo assim, ocorre o reforço de uma formação fragmentada e tecnicista, não havendo comprometimento com o SUS e com as necessidades da população. A Universidade deve participar, através da formação profissional, da composição de cenários e situações, das quais exista a interdisciplinaridade, a multiprofissionalidade do trabalho, a apropriação do sistema de saúde vigente no país e a interação entre universidade e sociedade ${ }^{2}$.

A partir deste cenário, em que foram expostas as políticas de integralidade à saúde, com seus princípios e diretrizes, as dificuldades de inserção da integralidade no cenário da saúde e o modelo complementar da iniciativa privada, o presente estudo tentará responder se o cenário de ensino, como instituição privada que presta assistência em saúde, atua na formação profissional e serve de espaço de integração entre eles (cenário e a população) e se está pautada sob o parâmetro da integralidade. Poderemos perceber se, haverá ou não, a necessidade de mudanças pedagógicas e estratégicas, que permitam que seja incorporado o conceito da integralidade desde o início da graduação, e que os cenários práticos sejam modificados e adequados, de acordo com a saúde vigente no país.

O objetivo do estudo foi verificar se as propostas presentes nos documentos que nortearam a concepção e implantação do cenário de ensino foram efetivadas de acordo com as premissas de integralidade de atenção à saúde 


\section{MÉTODO}

$\mathrm{Na}$ tentativa de buscar respostas para tais questionamentos, foram analisados os documentos diretivos da instituição de ensino, com o objetivo principal de verificar se tais normas permitem a proposição de estratégias agregadoras da integralidade na atenção à saúde. Como objetivos específicos, buscou-se compreender as bases de concepção do centro integrado de saúde (CIS). A partir do conceito de cenário de ensino), identificar os elementos norteadores do CIS e do projeto pedagógico.

Foram analisados o projeto pedagógico anterior àquele que permitiu a concepção do CIS. Na análise desses dois documentos pretende-se identificar se a concepção dos cursos avançou de uma perspectiva biologizante para outra que privilegie a integralidade de atenção à saúde. Foi investigado em que bases populacionais o perfil profissiográfico foi estabelecido e quais premissas filosóficas e epistemológicas norteavam cada um dos projetos. Além disso, a análise dos documentos investigou as estratégias metodológicas indicadas como ferramentas privilegiadas de ensino e como as práticas profissionais formadoras estavam contextualizadas.

Outra dinâmica envolvida nessa análise remete a identificação de indicadores da intersetorialidade e empoderamento do aluno para manejo da atenção primária à saúde. O levantamento desses aspectos permitiu analisar os valores que norteiam ou nortearam a concepção dos campos de estágio, em particular os serviços oferecidos dentro da Universidade pelo CIS.

Foi utilizada a análise do discurso, baseado na arqueologia do saber que terá como objetivo especificar um método de investigação que permite entender a ordem interna que constitui um determinado saber e detalhar a problemática da história contada pelos sujeitos ${ }^{3}$.

\section{RESULTADOS E DISCUSSÃO}

Desta maneira, a análise discursiva documental teve seu início pelo Plano de Desenvolvimento Institucional (PDI), este documento esteve validado institucionalmente entre os anos 2008 e 2012. Contudo, ao que parece, tal documento ainda é o de referência na instituição.

Neste trabalho, procuramos identificar a presença do conceito integralidade nos documentos, de forma objetiva e explícita ou de forma subjetiva e implícita; compreender as bases de concepção do CIS; identificar os elementos norteadores de CIS e do projeto pedagógico e analisar se os documentos permitem a integralidade ou se este pilar ficou obscuro.

O presente estudo objetivou, através de uma pesquisa documental, verificar se os documentos que concebem o CIS, que é um centro de atendimento clínico da cidade de São Paulo, proposto pela Escola de Ciências da Saúde e pertencente a uma universidade particular, prevê a proposição de estratégias concebidas a partir da integralidade de atenção à saúde.

A partir deste momento, discorreremos em capítulos o PDI, a fim de facilitar didaticamente a compreensão do estudo. No capítulo 1, serão expostos alguns dos principais elementos discursivos do
PDI, convergentes com os principais elementos discursivos sobre a integralidade.

A análise do PDI foi iniciada pelo perfil institucional, por externar uma preocupação com as ações dos profissionais da área da saúde. Nela, se percebe certo cuidado com as comunidades locais, a qualidade de vida e a saúde integral destes atores sociais; aspectos que apresentam uma articulação com os ditames da 13a Conferência Nacional de Saúde (CNS), onde postula a "articulação entre universidades, secretarias e movimentos sociais"'

Tivemos neste momento um primeiro esboço sobre o uso do termo integralidade, mas ainda acanhado e superficial.

A missão institucional enfatizou a visão humanística do ser. Humanização é tema tão importante que foi elemento de discussão da $11^{\text {a }}$ CNS, nela se discutiu, dentre outras coisas a "construção de um sistema de saúde capaz de responder adequadamente, com qualidade e humanização, às necessidades da população brasileira" ${ }^{\text {" }}$

Esta colocação dá certo tom para a integralidade, de forma um pouco mais objetiva.

Os objetivos e metas da instituição descreveram elementos que contemplam os ditames constitucionais e da integralidade, enfatizados desta forma:

respeitar os princípios universais de responsabilidade e liberdade de pensamento, direitos básicos do homem; contribuir para o fortalecimento dos laços de solidariedade entre todos os integrantes da comunidade acadêmica, tendo como parâmetro uma postura holística; promover o ensino superior, a pesquisa e a extensão, em diferentes campos do conhecimento integral da comunidade de sua área de influência, com vistas ao bem estar social, político, econômico e espiritual do homem; exercer o papel crítico em relação à sua própria identidade e às suas funções, bem como em relação á identidade e às funções da sociedade, a saber: políticas, econômicas, sociais, culturais e espirituais; preservar os valores e tradições morais, cívicas e espirituais, tendo em vista uma sociedade mais justa ${ }^{6}$.

Apesar de não declamarem explicitamente serem estas ações, baseadas sob a ótica da integralidade, percebemos claramente ações conformadas com as deste ente constitucional, onde se destaca a postura holística, as funções da sociedade e a visão de sociedade mais justa ${ }^{7,8}$.

Em outro momento, a PDI relata que a ampliação e consolidação de ações envoltas pelo compromisso social da instituição para com a sociedade é parte fundamental no processo de desenvolvimento da formação discente, ultrapassando as práticas complementares, com vistas para ações de cunho social e de cidadania ativa, estes elementos prezam o compromisso social interligando educação, formação profissional e sociedade, incitando conjuntamente o agir, fazer sair do papel, das folhas da burocracia as ações propostas. Atributos inerentes à integralidade $\mathrm{e}^{4,5,7}$

A inserção da instituição nas localidades e regiões é outra preocupação do PDI, tal documento entende que a sua inserção 
interfere na dinâmica dos bairros e do entorno como um todo, sendo fundamental existir uma interconexão entre instituição e moradores dos bairros. Encontramos nestas palavras convergências discursivas como as de Paim ${ }^{1}$ para com o princípio da integralidade no que tange a participação da comunidade nas ações continuadas da instituição.

O capítulo 2 se refere ao Projeto Pedagógico Institucional (PPI), este capítulo descreve trechos do PPI original, e como este documento (PPI) será analisado na integra mais a frente, não citaremos os recortes do PDI.

Os capítulos 3, 4, 5, 6, 7, 9 e 10 do PDI referem-se a outros elementos constitucionais que não interessam serem esclarecidos neste estudo.

O Capítulo 8 mereceu menção, por tratar da Infraestrutura Física e Instalações Acadêmicas e o CIS não figurou entre as instalações. Entretanto, existe uma explicação cabível: o documento exposto iniciou seu mandato em 2008 e como a criação do CIS (como veremos abaixo) se dá no ano de 2010, é compreensível não vê-lo entre os figurados.

Neste momento, discorreremos sobre o que encontramos na análise do discurso do PDI. O primeiro objetivo do estudo foi identificar a presença da integralidade nos documentos de forma objetiva e explícita ou subjetiva e implícita. A partir desta análise, foi possível perceber que o princípio da integralidade aparece, ora com força e poder discursivo, ora de maneira mistificada e obscura, não se pode, no entanto, dizer se o princípio da integralidade foi o parâmetro norteador da construção de tal documento.

Deste modo, firmamos que a integralidade se faz presente, isto ficou claro, mas com roupagem por vezes camuflada, ficando implícita e obscura sua participação nos ditames institucionais.

O segundo objetivo tratou de identificar os elementos norteadores do CIS e do projeto pedagógico. O PDI não cita as prerrogativas do CIS, mesmo assim a análise se seguiu por entendermos ser válido para o estudo compreender as prerrogativas institucionais que conforma, ou ao menos, deveriam conformar e nortear o CIS, lembrando que discorreremos sobre o PPI mais a frente.

Por fim, propomos analisar se este documento permite a integralidade. De fato, que sim, tal documento até aqui tem permitido ações em conformidade com o princípio da integralidade. Porém, mais uma vez, evidenciamos que este princípio não fora firmado de maneira explícita e objetiva, e, sim, em caráter implícito e subjetivo.

Agora, percorreremos os caminhos do Projeto Pedagógico Institucional (PPI), ele está inserido no PDI, como também, presente em documento próprio, portanto, analisaremos o documento próprio do PPI por compor na integra todo seu acervo institucional, diferente do PDI que suscita trechos do PPI.

O PPI é um documento norteador de todas as ações pedagógicas desenvolvidas na Universidade. O propósito do PPI é projetar metas e ações orientadoras da política da universidade. Porém, o PPI deixa claro que não estabelece regras fixas para os projetos pedagógicos de cada curso oferecido, mas convergem pontos comuns entre eles.

Dentre as convergências norteadoras está o envolvimento ativo e efetivo de todos os atores envolvidos nos diversos e complementares segmentos da universidade (alunos, professores, equipe técnica, administrativa e gestora), que deverão estar pautados em pilares (legais, históricos, técnico-pedagógicos, estruturais e econômicos), este é o sustentáculo de suas ações institucionais. No entanto, fica a pergunta: será que dentre estes pilares está à integralidade?

Este envolvimento anseia o educar, nos alunos, sob o prisma da cidadania, fundamentado em valores como a formação do homem integral e compromissado com o processo histórico, sociocultural e político da qual fazem parte. Elementos claramente consonantes com a integralidade ${ }^{9,10}$.

No intuito de conformar esta perspectiva, o PPI baseou-se na tríplice finalidade da educação, atribuindo sua existência em função da pessoa, da cidadania e do trabalho, visando preparar o aluno a partir da realidade presente no interior e exterior da Universidade, sob a perspectiva de atender as múltiplas demandas sociais e culturais da população sob este prisma. Dedução que conforma as prerrogativas da integralidade ${ }^{8,11}$.

Um trecho em específico do PPI será citado diretamente, entendendo que este recorte sintetiza os elementos fundamentais da integralidade, vejamos:

consoantes aos seus princípios filosóficos, a instituição entende que é preciso promover a formação de jovens competentes, humanizados, éticos, críticos, que reconheçam a pluralidade de ideias e comprometidos com o seu desenvolvimento e com odesenvolvimento do país, que analisem e reflitam sobre o contexto social e assumam o seu papel na transformação da sociedade ${ }^{6}$.

Este discurso é muito representativo de ações pautadas pela integralidade e remete a outro, pensado por Ceccim e Feuerwerker ${ }^{12}$ :

a formação para a área da saúde deveria ter como objetivos a transformação das práticas profissionais e da própria organização do trabalho, e estruturar-se a partir da problematização do processo de trabalho e sua capacidade de dar acolhimento e cuidado às várias dimensões e necessidades de saúde das pessoas, dos coletivos e das populações ${ }^{12}$.

No entanto, não fica claro se tal discurso documental baseou suas falas nos preceitos da integralidade, deixando em aberto este questionamento.

O trecho que apontaremos agora parece remeter aos objetivos e metas do PDI. Apresentaremos trechos que revelam este parentesco:

deve oferecer aos estudantes as condições para a realização de experiências significativas na sua área de conhecimento e no campo da sua formação cultural, social e de cidadania, dando-lhe condições de refletir sobre as questões da atualidade e compreender a realidade de forma integrada. [...] Para a sociedade, a extensão deve disponibilizar conhecimento, por meio de programas, cursos, projetos, prestação de serviços e eventos, que contribuam ativamente com a melhoria da qualidade de vida da comunidade ${ }^{6}$. 
Para conformar esta citação, revisitamos o estudo de Paim ${ }^{1}$ que ditou o "desenvolvimento e fortalecimento de uma cultura de vida e da saúde" e "atenção às necessidades e demandas em saúde", ambas remetendo ações de cunho constitucional e harmoniosas com a citação acima.

A Responsabilidade Social é outro elemento que merece destaque por incitar o desenvolvimento social, através de parcerias diversas, em diversas áreas do conhecimento. Para exemplificar a importância deste cenário, apresentaremos alguns elementos pertinentes, segundo o PPI.

Esta concepção de Responsabilidade Social leva a instituição a ouvir os diferentes atores envolvidos (dirigentes, funcionários, professores, alunos e comunidade externa), de modo a incorporar suas manifestações no planejamento de suas ações, suas políticas, suas práticas e suas atitudes, dentro dos limites institucionais e no estrito cumprimento das funções para as quais foi criada.

Nesse sentido, para a Universidade, o tema responsabilidade social permeia todo o planejamento institucional, permitindo à comunidade interna e externa tanto para praticá-la quanto vivenciar os resultados dessa opção institucional, fortalecendo o seu princípio pedagógico de ir além do assistencialismo e promover a responsabilidade Social, baseada na formação de uma atitude pessoal e profissional sobre este tema ${ }^{6}$.

Esta citação incita, mais uma vez, o agir; incita passar do processo de aprendizado passivo, como ouvinte, para o ser ativo e atuante, conformando sua perspectiva com a de Souza et al. ${ }^{12}$.

O PPI apresenta agora a proposta de Delors ${ }^{13}$, como um dos conceitos fundamentais para responder ao desafio de educar e formar um indivíduo ao longo de sua vida, para isto demonstraremos os quatro pilares descritos por Delors ${ }^{13}$ e apresentado no PPI:

aprender a conhecer (que significa dar-se conta das cegueiras do conhecimento - erro e ilusão) e procurar maneiras de distinguir o real do ilusório. Desenvolver no aluno a capacidade de estabelecer pontes entre os diferentes saberes, entre esses saberes e suas significações na vida cotidiana, entre esses saberes e as capacidades humanas interiores. Estabelecer um espaço transdisciplinar que dá o significado aos esforços disciplinares. Aprender a conhecer é aprender a aprender.

Aprender a fazer é a capacidade de ser criativo em todas as ações, é fazer com que o aluno incorpore habilidades, é desenvolver a flexibilidade de aquisição da profissão e de outros conhecimentos que se agreguem a essa profissão, ampliando seu campo de ação. Aprender a fazer implica o desenvolvimento do espírito de colaboração e equidade.

Aprender a viver juntos significa, em primeiro lugar, respeitar as normas que regulamentam as relações entre os seres que compõem uma coletividade, de forma a que sejam verdadeiramente compreendidas e incorporadas como valores do grupo. Viver junto é desenvolver a difícil arte da convivência, é mais do que tolerar o outro, é ser com o outro. Significa desenvolver os valores do respeito, do equilíbrio, do diálogo, da compreensão e cooperação, a partir da percepção da interdependência, da administração dos conflitos e do anseio pela não violência.

Aprender a ser começa com o aprendizado do que a palavra "existir" tem para cada um; é descobrir a harmonia e desarmonia entre o individual e o coletivo de cada um; é descobrir o que nos motiva, o que tem valor para nossa vida. Aprender a ser é buscar, estudar e difundir práticas que contribuam para o aprimoramento e o crescimento pessoal e transpessoal ${ }^{6}$.

Todas estas perspectivas emergem uma gama inesgotável de elementos que integram a integralidade, sendo necessário agregar pensamentos de vários autores para conseguir conformá-la, como é o caso da transdiciplinaridade e da preservação do ser holístico, instigada por Souza et al. ${ }^{7}$, o humanismo referido na $13^{\text {a }} \mathrm{CNS}$, a interação entre profissional de saúde e usuário descrito por Ceccim e Feuerwerker ${ }^{12}$, desenvolvimento do diálogo e da conversação, inseridos no discurso de Mattos $^{9}$, os diferentes campos sociais que interferem no existir em sociedade, instigado por Scliar ${ }^{8}$, elementos característicos da integralidade.

Novamente, foram apresentados elementos que conformam as premissas da integralidade, porém, sua roupagem é atribuída a diversos atores, não apenas a este princípio. Aqui, podemos encontrar a história, a cultura e as tradições mencionadas por Scliar ${ }^{8}$ o melhoramento das condições de vida referidas por Paim ${ }^{1}$, o desenvolvimento do ser humano, acolhido no CONASS $^{11}$, a interação entre as pessoas, discorridas por Ceccim e Feuerwerker ${ }^{12}$. Enfim, é preciso novamente somar muitos pensamentos para alcançar tão importante discurso.

Em suma o PPI em diversos momentos expostos aqui e em outros mantidos no próprio documento, não pela "insignificância", mas pela coincidência de ideias, que tornariam demasiadamente cansativa expô-las sempre que surgissem, apresentaram clara e evidente preocupação em construir no aluno e futuro profissional de saúde, pensamentos baseados em princípios filosóficos humanísticos, éticos, espirituais, culturais, de cidadania, de respeito ao próximo e ao meio ambiente, coletivos e regionais, consonantes com atitudes, também baseadas nestes preceitos a fim de atender as necessidades do cotidiano das comunidades e do entorno. Estes elementos são claramente consonantes com o princípio da integralidade, contudo, mais uma vez não é exposto com exatidão se tais elementos são norteados pelo princípio da integralidade.

Para analisar as bases de concepção do CIS, foi preciso recorrer a outro documento. O documento que melhor comporta tais características, e o único encontrado, é o documento denominado "CIS - Centro Integrado de Saúde".

A instituição do Centro Integrado de Saúde foi inaugurada no dia 26 de maio de 2010, sendo considerado um dos centros clínicos mais amplos da cidade de São Paulo com 2,8 mil metros quadrado de área construída. O CIS está localizado no Bairro do Brás e contou com um investimento de R 5 milhões da instituição de ensino para sua construção. A sua estrutura física conta com 47 consultórios, dois ginásios terapêuticos, uma piscina, entre outras salas. 
$\mathrm{O}$ volume de pessoas que podem ser atendidas chega a 700 pessoas por dia. As especialidades disponíveis para a população são constituídas por profissionais de medicina, fisioterapia, nutrição, enfermagem, naturologia, podologia, quiropraxia, farmácia, psicologia e educação física. O diferencial deste centro é $o$ atendimento integrado, que envolve diversas especialidades das diversas ciências da saúde, dentro de um mesmo espaço. Um grande intento nesta perspectiva é justa prestação de serviçosintegrados e tão aclamados por Hartz e Contrandiopoulos ${ }^{13}$.

O CIS tem por base de intervenção os casos de baixa complexidade e os serviços de prevenção. Os serviços prestados pelo CIS atuam em duas frentes, serviços com preços acessíveis e programas de atendimento a comunidade com gratuidade nos serviço. Serviços elementares que compõem uma gama importante de acesso aos serviços de saúde, perspectiva que facilita o acesso da comunidade e prevista pela constituição ${ }^{10}$.

A missão do CIS é a de contribuir na formação do profissional de saúde, promovendo programas de prevenção e atendimento primário, objetivando a qualidade de vida da comunidade. Esta visão afirma um dos compromissos do PPI, que é a valorização do cuidado para com o indivíduo, enquanto ente social e que necessariamente precisa ser entendido desta maneira. Preservando mais uma vez os dizeres de Paim ${ }^{1}$ sobre a construção de ambientes saudáveis para a população.
A Visão do CIS é de tornar-se um centro de referência na prestação de serviços primários na saúde, com responsabilidade social, ambiental e auto sustentabilidade ${ }^{14}$.

Já os valores institucionais partem da premissa que a aprendizagem e desenvolvimento de pessoas, o humanismo, a ética e justiça, o respeito à vida e ao meio ambiente, o pioneirismo e busca contínua das fronteiras do conhecimento devem ser efetivados e somados com atitude. Entendemos neste sentido uma nítida interlocução entre o projeto pedagógico, com seu espírito de valorização do ser enquanto profissional atuante e do ser enquanto ente social usuário, e do CIS, como centro clínico intermediador destas ações ${ }^{14}$.

A partir da leitura e análise deste enxuto, porém, bem articulado documento compositor estrutural dos preceitos do CIS, foi possível melhor compreender a sua lógica estrutural, e reconhecer alguns de seus regentes constitucionais e princípios norteadores. De certa forma os descritos no documento abarcam algumas das premissas constitucionais, dentre elas a integralidade. No entanto, não é possível fazer análise de alguns pontos cruciais na dinâmica do CIS.

A não compreensão conceitual de integralidade/interdisciplinaridade gera uma prevalência de um olhar nas atenções secundária e terciária à saúde.

O corpo docente detém isenção de culpa devido à ambiguidade dos conceitos. Mas, em decorrência disso, o corpo discente herda a incompreensão na sua formação o que refletirá para a sua vida profissional.

\section{REFERÊNCIAS}

1. Paim JS. Desafios para a saúde coletiva no século XXI. Ed. Edufba. Salvador: Edufba; 2006

2. Saldanha OMFL. Clínica-escola: discussão e desafios na educação superior da saúde. Tese (Doutorado) - Universidade Federal do Rio Grande do Sul, Porto Alegre, 2013.

3. Foucault M. A arqueologia do Saber. Rio de Janeiro: Forense Universitária, 2009.

4. Brasil. Ministério da Saúde. Conferência Nacional de Saúde Relatório Final da $13^{a}$ Conferência Nacional de Saúde: Saúde e qualidade de vida: políticas de estado e desenvolvimento. Brasília: Ministério da Saúde; 2008.

5. Brasil. Ministério da Saúde. Conferência Nacional de Saúde. $11^{a}$ Conferência Nacional de Saúde, Brasília 15 a 19 de dezembro de 2000: o Brasil falando como quer ser tratado: efetivando o SUS: acesso, qualidade e humanização na atenção à saúde com controle social: relatório final. Brasilia: Ministério da Saúde; 2002.

6. Universidade Anhembi Morumbi. Plano de Desenvolvimento Institucional 2008-2012. São Paulo: 2007.

7. Souza MC, Araújo TM, Reis Júnior WM, Souza JN, Vilela ABC, Franco TB. Integralidade na atenção à saúde: um olhar da equipe de saúde da família sobre a fisioterapia. Mundo Saúde. 2012;36(3):452-60.
8. Mattos RA. Os sentidos da integralidade: algumas reflexões acerca de valores que merecem ser defendidos. In: Pinheiro R, Mattos RA, organizadores. Os sentidos da integralidade na atenção e no cuidado à saúde. 8ed. Rio de Janeiro: ABRASCO; 2009.

9. Brasil. Ministério da Saúde. Conferência Nacional de Saúde. Relatório final da $10^{a}$ Conferência Nacional de Saúde. Brasília: Ministério da Saúde; 1998.

10. Brasil. Conselho Nacional de Secretários de Saúde. Legislação do SUS / Conselho Nacional de Secretários de Saúde. Brasília: CONASS; 2003

11. Ceccim RB, Feurewerker LCM. O quadrilátero da formação para a área da saúde: Ensino, gestão, atenção e controle social. Physis. 2004;14(1):41-65

12. Delors J. Educação: um tesouro a descobrir. São Paulo, Cortez; 1998.

13. HartzZMA, Contandriopoulos AP. Integralidade daatençãoeintegração de serviços de saúde: desafios para avaliar a implantação de um "sistema sem muros". Cad Saúde Pública. 2004;20(suppl.2):S331-6. http://dx.doi.org/10.1590/S0102-311X2004000800026

14. Neves D. A integralidade no setor privado da saúde: um olhar acerca de um centro clínico universitário. Monografia (Curso de pós-graduação) - Universidade Anhembi Morumbi, São Paulo, 2014. 